\title{
De la crisis del aura a la liberación del aparato cinematográfico: Walter Benjamin y Dziga Vertov ${ }^{1}$
}

\section{Walter Benjamin and Dziga Vertov: From the Crisis of Aura to the Liberation of the Cinematographic Apparatus}

\author{
Álvaro Villegas \\ Universidad Nacional de Colombia. Medellín, Colombia. \\ aavilleg@unal.edu.co
}

\section{Resumen}

Durante buena parte del siglo XX el cine se convirtió en un aparato que participó decisivamente en los modos de percepción y de relación humanos. A partir de los argumentos de Walter Benjamin, se plantea cómo el aparato cinematográfico profundizó la crisis del aura, al hacer de la reproductibilidad la forma de existencia privilegiada de las "nuevas artes" y una modalidad de recepción cada vez más importante de las artes tradicionales. Esto abre la posibilidad de disolver las formas burguesas y reutilizar sus ruinas, lo cual implica la adaptación de los medios de producción cinematográficos a los fines revolucionarios. Será Dziga Vertov, quien a través de sus manifiestos, ensayos y películas cumplirá esta tarea al buscar liberar al cine del capital, del arte, de la percepción humana, y del espacio y el tiempo, en pos de un desciframiento del mundo sensible que permitiera el despertar colectivo.

Palabras clave: Walter Benjamin, Dziga Vertov, cine, estética.

\begin{abstract}
During most of the twentieth century cinema became an apparatus that configured modes of perceiving and relating. This paper takes as a point of departure Walter Benjamin reflections on how the cinematographic apparatus intensified the crisis of aura by making reproducibility the privileged form of existence of the "new arts" and a more important modality of reception for traditional arts. This opens up the possibility of dissolving bourgeois forms and reuse their ruins, which implies the adaptation of cinematographic production media to revolutionary ends. It is Dziga Vertov who, through his manifestos, essays and movies, accomplishes this task by trying to free cinema from capital, art and human space and time, in search of a deciphering of the sensitive word that allows for collective awakening.
\end{abstract}

Keywords: Walter Benjamin, Dziga Vertov, Cinema, Aesthetics.

1 Este artículo es resultado de la investigación "Sinfonías urbanas: montaje y regímenes sensibles en el cine" (Cód. 14806), financiada por la Universidad Nacional de Colombia. 


\section{Agradecimientos}

Agradezco a Daniel Jerónimo Tobón la traducción del resumen al inglés y las discusiones sobre Walter Benjamin, Dziga Vertov y las relaciones entre estética y cine.

\section{I}

Pensar el cine es hoy más necesario que nunca. De hecho es posible que sea el mejor momento para esta reflexión, puesto que poseemos las ventajas de una mirada distante. Si tomamos algunas de las periodizaciones que se han realizado sobre la imagen, se llega rápidamente a la conclusión de que el cine ya no es el medio en que "todos los problemas del arte actual encuentran su formulación definitiva" y en el que se despliegan "todas las formas perceptivas, pautas y ritmos preformados en las máquinas actuales" como lo había planteado, originalmente en la década de 1930, Walter Benjamin (2007a, 399-400, énfasis agregado, Pezzella 2004, 13). La inactualidad de la imagen fílmica es expresada de diversas formas, Laurent Gervereau (2003) divide las edades de la imagen industrial en la era del papel (1848-1916), la era de la proyección (1916-1960) y la era de la pantalla (1960-2000); José Luis Brea (2010) propone un recorrido que va de la imagen-materia, pasa por el film y llega a la e-image (imagen electrónica); Régis Debray plantea, por su parte, la existencia de tres regímenes: el del ídolo, el del arte y el de lo visual y nos recuerda que "Lo visual comienza donde termina el cine" (Vida y muerte de la imagen 251).

El cine ocupa, pues, un carácter residual dentro de la producción, circulación y consumo contemporáneo de imágenes en movimiento, al tiempo que se ha transformado en un medio integrado a las nuevas dinámicas digitales de la cultura y ha dejado atrás, en buena medida, su carácter mecánico. En este sentido pensar el cine hoy, es reflexionar desde una época situada después del cine (Quintana 2011), en la cual el debate sobre la "muerte del cine" ha revitalizado la reflexión sobre las posibilidades y los límites del medio cinematográfico (Santa Cruz 2014). La apuesta de este artículo es asumir este reto de la mano de Walter Benjamin (1892-1940) y, en menor medida, de Dziga Vertov (1896-1954), quienes vivieron y adelantaron su trabajo en la época del aparato cinematográfico, o para formularlo de otra manera, cuando el cine era el principal aparato de configuración técnica de la sensibilidad de masas (Déotte 2012 y 2013a y 2013b). Ambos se preocuparon por la ampliación del campo de la visibilidad, por las transformaciones de la memoria, la percepción y la sensibilidad y por la necesidad de transformar al artista en un productor. En este orden de ideas, se plantea que si bien las relaciones explícitas entre ambos fueron débiles -el primero cita al segundo de pasada y Vertov no menciona en sus diarios a Benjamin-, las películas dirigidas por Vertov, en especial El hombre de la cámara pueden ser pensadas como una forma de realizar el proyecto benjamineano de hacer del cine un aparato emancipador en un contexto post-aurático. 
Denis Abramovich Kaufman más conocido como Dziga Vertov fue, sin duda alguna, uno de los cineastas soviéticos más importantes de su generación y una de las figuras centrales en la emergencia del cine documental durante las décadas de 1920 y 1930, con largometrajes como Cine-ojo (1924), La sexta parte del mundo (1926), El undécimo año (1928), El hombre de la cámara (1929), Entusiasmo (1931) y Tres cantos para Lenin (1934), a la par de su trabajo en el noticiario Kino-pravda entre 1922 y 1925.

Jacques Aumont ha planteado que Vertov se propuso tomar el cine en donde lo habían dejado los hermanos Lumière para ponerlo al servicio de una causa científica y política (Las teorías de los cineastas 120). En palabras de Noël Burch se trataba de hacer tabula rasa de la historia del cine, para limpiar los ojos del proletariado("Film's Institutional Mode of Representation and Soviet Response" 93). Con estos objetivos, el cineasta se rodeó de una serie de colaboradores que llamó kinoks y que debían perseguir "la vida cotidiana y su organización". Su esposa y editora Elizaveta Svilova (1900-1975) y su hermano y operador de cámara Mikhail Kaufman (1897-1980), serían sus compañeros más cercanos y formarían a su lado el autodenominado Consejo de los tres.

Por su parte, Walter Benjamin fue ante todo un pensador heterodoxo, quienes lo conocieron y luego se convirtieron en comentaristas de su vida, resaltaron la amplitud y el carácter difícilmente clasificable de sus preocupaciones intelectuales ${ }^{1}$. Tal vez la mejor forma de definirlo sea como un crítico de la cultura judío-alemán, quien estuvo en un primer momento interesado principalmente en investigar la literatura de su país, los cual produjo obras como El concepto de crítica de arte en el Romanticismo alemán, Las afinidades electivas y El origen del Trauerspiel alemán. A mediados de la década de 1920 se acercó al marxismo, del cual desarrollara una variante que se podría denominar indudablemente como herética, al vincular los planteamientos del materialismo dialéctico con el misticismo judío, la metafísica romántica y las prácticas artísticas de vanguardia.

Las reflexiones benjaminianas buscan captar la totalidad en los fragmentos y lo teórico en lo fáctico, desde una perspectiva atenta a una serie de fenómenos considerados generalmente menores, banales o caducos. El mismo autor lo hacía explícito cuando en sus notas para el Libro de los pasajes planteaba: "Método de trabajo: montaje literario. No tengo nada que decir. Sólo que mostrar. No hurtaré nada valioso, ni me apropiaré de ninguna formulación profunda. Pero los harapos, los desechos, esos no los quiero inventariar, sino dejarles alcanzar su derecho de la única manera posible, empleándolos" ("Teoría del conocimiento, teoría del progreso" 462). A pesar de que este escrito nunca fue publicado, es posible afirmar que Benjamin si logró escribir y publicar un libro-montaje, éste fue Calle de dirección única (2010) cuya edición

1 Adorno (1970), Arendt (1971), Bloch (2011), Scholem (1998). 
original es de 1928 y, de acuerdo a Jennings (2010), es el resultado de las discusiones que Benjamin mantuvo con los integrantes del "Grupo G” en Berlín, el cual estuvo conformado entre otros, por Hans Richter, Kurt Schwitters, Raoul Haussmann, Hans Arp, George Grosz, John Heartfield, Hannah Höch, El Lissitzky, Lazlo Moholy-Nagy, Naum Gabo, Tristan Tzara y Man Ray. En este orden de ideas, la crítica de la cultura trabajaría de forma semejante a la de muchos artistas de las vanguardias históricas y a la de los cineastas, también tendría profundas semejanzas operativas con el oficio de trapero y con la capacidad mimética de los niños, quienes usarían de formas nuevas los fragmentos, ruinas y desechos del mundo moderno.

\section{III}

La tarea que se impone cuando pensamos con Benjamin el aparato cinematográfico es justamente realizar un montaje, buscar entre sus textos los fragmentos que le dedicó $\mathrm{y}$ asociarlos de forma tal que desplieguen su poder destructivo y constructivo. Esto se debe a que si bien es posible encontrar un par de escritos que se ocupan explícitamente del cine ("La situación del arte cinematográfico en Rusia” y "Réplica a Oscar A. H. Schmitz”), la mayoría de los planteamientos sobre éste se encuentran dispersos en textos que desarrollan otras preocupaciones. Para comenzar este montaje, nos remitiremos a "El ensayo sobre la obra de arte en la época de su reproductibilidad técnica”, en el cual se planteó la necesidad de introducir a la teoría del arte una serie de conceptos que fueran inutilizables para los fines del fascismo. Este propósito se enfrentó a un reto, no existía una teoría marxista del arte propiamente dicha, en tanto fue imposible que Marx la desarrollara, pues las transformaciones superestructurales tuvieron una temporalidad diferente a la de los cambios infraestructurales. Las primeras se expresarían en su madurez cuando ya Marx había muerto:

\footnotetext{
Hacia el 1900, la reproducción técnica había alcanzado un nivel que no sólo comenzaba a convertir en su objeto el conjunto de las obras de arte tradicionales, sometiendo su efecto a las transformaciones más profundas, sino que conquistó su lugar propio entre los procedimientos artísticos vigentes ("La obra de arte en la época de su reproductibilidad técnica”, tercera redacción 53).
}

En este sentido, toda teoría del arte debería estar apoyada en una historia del arte no-burguesa que permitiera comprender la aparición de nuevas manifestaciones y los cambios en las formas tradicionales. En este punto en particular, Marx y Engels habían dado algunas pistas importantes que se podían resumir en cuatro planteamientos básicos: 1) la historia del arte no debe ser una historia de la acumulación de obras, etapas y estilos, ni la superación de unas por otras; 2 ) las nociones de autonomía, creatividad y genialidad deben ser descartadas; 3) la historia del arte debe estar íntimamente relacionada con las preocupaciones técnicas, económicas, sociales y 
políticas; 4) en cada obra se hace presente su pre-historia y su post-historia, lo cual obliga al historiador a estar atento a los constantes cambios en la materialidad y en las formas de apropiación de las obras de arte, los cuales las tornarían inestables y dinámicas. Estos planteamientos hacían necesario un acercamiento materialista, dialéctico e histórico que estaba aún por construir.

Aún queda por resolver por qué el año de 1900 es asumido como el momento de una discontinuidad histórica. La tercera redacción de "El ensayo sobre la obra de arte en la época de su reproductibilidad técnica” comienza con un epígrafe de Paul Valéry, en el cual se señalaba que ni la materia, ni el tiempo, ni el espacio eran en ese momento -1928-, lo mismo que hacía 20 años; ese cambio modificaba por completo el concepto de arte. En un fragmento no citado por Benjamin, Valéry agregaba:

De entrada, indudablemente, sólo se verán afectadas la reproducción y transmisión de las obras. Se sabrá cómo transportar y reconstituir en cualquier lugar el sistema de sensaciones -o más exactamente de estimulaciones- que proporciona en un lugar cualquier un objeto o suceso cualquiera. Las obras adquirirán una especie de ubicuidad. Su presencia inmediata o su restitución en cualquier momento obedecerán a una llamada nuestra. Ya no estarán sólo en sí mismas, sino todas en donde haya alguien y un aparato. Ya no serán sino diversos tipos de fuente u origen, y se encontrarán o reencontrarán íntegros sus beneficios en donde se desee. Tal como el agua, el gasto o la corriente eléctrica vienen de lejos a nuestras casas para atender nuestras necesidades con un esfuerzo casi nulo, así nos alimentaremos de imágenes visuales o auditivas que nazcan y se desvanezcan al menor gesto, casi un signo. Así como estamos acostumbrados, si ya no sometidos, a recibir energía en casa bajo diversas especies, encontraremos muy simple obtener o recibir también esas variaciones u oscilaciones rapidísimas de las que nuestros órganos sensoriales que las recogen e integran hacen todo lo que sabemos. No sé si filósofo alguno ha soñado jamás una sociedad para la distribución de la Realidad Sensible a domicilio ("La conquista de la ubicuidad" 131-2).

Por supuesto, Valéry toma como modelo para su predicción la reproducción técnica del sonido, que ya contaba con la radiodifusión y el gramófono, al tiempo que reconocía que estas transformaciones eran todavía incipientes en la reproducción de la imagen. No obstante, para Benjamin la realidad visual ya había penetrado las profundidades de los domicilios decimonónicos con las tarjetas de visitas ("Pequeña historia de la fotografía" 377), primera forma verdaderamente industrial de la fotografía. La importancia de esta invasión al intérieur burgués radicaba en que se comenzaba un largo proceso de separación de lo reproducido de la tradición, puesto que por un lado se sustituía una presencia irrepetible por una masiva, y por el otro, actualizaba lo reproducido en cada encuentro entre el espectador y la reproducción. Este doble proceso tenía en el cine su fuerza más poderosa, "cuyo significado social, hasta en 
la más positiva de sus formas y justamente en ella, no resulta por cierto concebible sin incluir su aspecto destructivo, catártico: la liquidación del valor de la tradición dentro de la herencia cultural" ("La obra de arte en la época de su reproductibilidad técnica”, tercera redacción 55-6).

Dicha liquidación es, a su vez, el reverso de la crisis y renovación de la humanidad, impensable sin cambios profundos en la sensibilidad y la percepción, los cuales están condicionadas técnicamente. El surgimiento de una nueva sensibilidad está vinculado a la conversión de la técnica en una segunda naturaleza y a la emergencia de un nuevo sujeto histórico: las masas, que no deben ser confundidas con el proletariado, puesto que reúnen a un colectivo mucho más amplio e informe que éste. Las masas tendrían una sensibilidad exacerbada para lo homogéneo del mundo, a través de su deseo de acercamiento constante a lo reproducido y de repetibilidad infinita de la reproducción, ellas instaurarían otra forma de existencia de las obras de arte y una nueva modalidad de relacionarse con estas.

\section{IV}

Hasta este momento nos hemos referido, sin mencionarla por su nombre a la noción de aura. Esta noción se encuentra presente en varios textos ${ }^{2}$ y su definición presenta unas ligeras pero significativas variaciones, el aura hace referencia principalmente a: un tejido particular de espacio y tiempo que hace posible la irrepetible aparición de una lejanía por cercana que pueda estar, 2) una forma de percepción basada en la devolución de la mirada, 3) un halo, éter o sustancia que rodea a una persona o un objeto de percepción, encapsulando su individualidad y autenticidad (Hansen, Cinema and Experience 106).

Si tomamos la primera parte de la primera definición - una trama particular de espacio y tiempo-, entramos al terreno de las formas a priori de la sensibilidad, condición de posibilidad de toda experiencia, en obvia referencia a Kant (Crítica de la razón pura). Si a esto le sumamos la segunda parte -la irrepetible manifestación de una lejaníaestamos planteando la necesidad de un tiempo de inmersión por parte del espectador en el objeto investido auráticamente, al tiempo que reconocemos que la distancia se mantiene a pesar de esa inmersión (Costello, "Aura, rostro, fotografía: releer a Benjamin hoy" 114-5). Desde esta perspectiva el objeto mantiene su opacidad, un poso de indescifrabilidad que excede la percepción y cognición cotidianas.

2 "Pequeña historia de la fotografía", "La obra de arte en la época de su reproductibilidad técnica" (primera y tercera redacciones), "Sobre algunos motivos en Baudelaire". 
Para Walter Benjamin la contemplación aurática de las obras de arte procede de su origen ligado al culto, en un primer momento mágico y luego religioso. El ritual, sería en su opinión, el lugar en el que la obra de arte tuvo su valor de uso originario ("La obra de arte en la época de su reproductibilidad técnica", tercera redacción 58). Este valor de uso ritual entra en crisis con la reproductibilidad técnica de las obras de arte, que tiene como primer umbral de no-retorno la aparición de la fotografía y que se profundiza con el cine, medio basado en principios fotográficos. La imagen de culto es inacercable, aunque el creyente la vea o incluso la toque, la imagen pertenece a otra esfera ontológica, a una a la cual no puede acceder o sólo lo puede hacer a través de múltiples mediaciones y en ocasiones especiales, que refuerzan justamente su carácter esotérico y, por tanto, lejano. Como ejemplo de esto Benjamin ("La obra de arte en la época de su reproductibilidad técnica", primera redacción 37) utiliza el arte religioso europeo que permanecía inaccesible a la mayoría de los fieles e incluso cuando estos podían acceder a él colectivamente, lo hacían a través de múltiples mediaciones jerarquizadas en momentos específicos y ritualizados.

Los procesos de secularización hacían más indeterminada y difícil la inaproximabilidad y la irrepetibilidad de las obras de arte, que se iba desplazando del reino de lo esotérico al dominio de lo exóterico, en el cual la irrepetibilidad empírica del creador, la naturalización de la "genialidad" o el culto profano a la belleza, tomaban el lugar del valor de uso ritual ("La obra de arte...", tercera redacción 58). La reproductibilidad de la obra de arte, finiquitaba este proceso y emancipaba por vez primera la obra de su existir subordinado dentro del culto, ya que incluso la autenticidad que se había convertido en sí misma en un culto cada vez más secularizado, entraba también en crisis, ya que el aquí y el ahora, que sustentaba la autenticidad, perdía relevancia.

No había un original posible, ya que no se trataba simplemente de que una obra pudiera ser reproducida -todo lo hecho por los seres humanos puede ser reproducido por ellos (“La obra de arte...", tercera redacción 52)-, sino que su carácter era y es ser reproducible; la reproducción no es un accidente ni una posibilidad, es la forma de existencia de las nuevas artes: fotografía y cine, y una modalidad de recepción cada vez más importante de las artes tradicionales. Esa reproducibilidad hace que prime entonces el polo expositivo, opuesto al polo de culto, que para Benjamin, como es posible inferir de lo expuesto hasta aquí, es también el polo de lo oculto, El acceso instantáneo, y en la medida de lo posible barato y fácil, a las obras por parte de las masas que buscan hacerlas suyas, poseerlas, verlas una y otra vez, es lo que caracterizará las formas de apropiación de las artes de la reproductibilidad técnica, se trataba, por supuesto, de una visualidad ampliada y generalizada, en la cual era central mirar, ser visto y hacer ver. Desde esta perspectiva, la cultura de masas hacía imposible la contemplación, o cuando menos provocaba y proclamaba su declive. Es importante recordar que la contemplación remite tanto a la contemplación de lo divino, como a la de las obras de arte parcialmente secularizadas, en un proceso que tendría su punto de partida en el Renacimiento. No se trata entonces, o no principalmente, de que 
unos objetos tengan aura y otros no, sino de una condición -sensible- de los sujetos, la cual posee una historicidad.

Esto nos lleva a plantear dos conclusiones provisionales: 1) las obras, singulares, únicas y auténticas, es decir, originalmente investidas de aura, sufren un proceso "desauratización", por supuesto, esto implica que el valor y el sentido de las obras de arte no es una esencia intransferible e inmutable, sino que está vinculada a su materialidad -que por supuesto sufre desgastes y mutaciones-, a las relaciones de propiedad en las que ha estado inserta, a las apropiaciones que ha sufrido e incluso a las copias que se han hecho de ella. Un ejemplo de esto podría ser la Gioconda cuyo "valor" actual no depende de su aura, sino justamente de su proximidad y repetibilidad, de su multiplicada potencia expositiva que la hace presente en numerosos objetos prosaicos y en multitud de pantallas; aunque también es indispensable mencionar que Benjamin plantea que la recepción de una obra de arte se produce en varios planos que están entre los polos del valor de culto y del valor de exposición, en este sentido toda recepción privilegiaría uno de estos polos, pero no borraría completamente al otro. 2) La noción de autenticidad también debe ser relativizada, en la tercera nota al pie de la tercera redacción de "El ensayo sobre la obra de arte en la época de su reproductibilidad técnica" Benjamin (54) se aclaraba que una obra medieval, la pintura de una virgen, por ejemplo, no era auténtica en el Medioevo, lo llegó a ser en el curso de los siglos, en especial en el siglo XIX; esta aparente paradoja tiene una explicación si volvemos a la formulación de que el valor de la obra no está inscrita en ella de una vez y para siempre, sino que depende de la historia en la que está inserta y que hizo, en este caso, de su procedencia medieval un hecho relevante sólo varios siglos después de ser pintada. Como lo ha expresado Barría, la obra de arte cobra un carácter único por su emplazamiento temporal que atestigua su autenticidad, pero este emplazamiento implica una relación retrospectiva con el objeto emplazado ("La producción de un desaparecimiento. Verdad, aura y técnica en Walter Benjamin” 198).

\section{V}

Para Walter Benjamin, el declive de la praxis ritual, lleva a la asociación de las obras de arte con la praxis política, especialmente con lo que denominó la estetización de la política, punto sobre el que se volverá luego. Totalitarismos, principalmente fascismos que buscaban transformar al estado en una obra de arte total que manipulara a los seres humanos, como los artistas manejaban sus materiales. El modelo aquí habría sido justamente, la autonomía del arte: el arte por el arte, que se transformaría en el campo político en la conversión de la razón de Estado en un fin en sí mismo. Sin embargo, tal vez sea más adecuada la visión de Theodor Adorno ("Sobre el carácter fetichista de la música y la regresión de la escucha”) quien planteó que el vínculo primordial se establecería con la praxis económica, en tanto toda obra estaría marcada por la 
forma-mercancía; vínculo que obviamente consideraría críticamente pero al que le reconocería un valor: el de mostrar la fetichización y vetustez de las formas artísticas canónicas, ya que a su juicio la "música seria" estaba tan sumida en la forma-mercancía como la "música ligera". Walter Benjamin, por su parte, encontraría en la mercantilización de las obras de arte, además de una posibilidad crítica un "principio de verdad", puesto que éstas serían producidas, distribuidas y consumidas de la misma forma que los objetos que las rodeaban, serían una expresión plenamente contemporánea con su época. El cine haría evidente esta situación en tanto era un arte completamente industrial, propio de una sociedad basada, justamente, en la producción industrial de inmensas cantidades de mercancías. Por supuesto, el cine tendría otras funciones durante la dictadura del proletario o en una sociedad sin clases, como lo ilustran las realizaciones de Dziga Vertov y los kinoks, pero en las sociedades capitalistas, ante todo, socavaría los cimientos del arte tal y como se entendía tradicionalmente, al tiempo que expresaría el afán de las masas por distraerse y las transformaciones perceptivas y memorísticas de la modernidad.

Estos planteamientos desarrollaban, en buena medida, varias de las ideas expresadas por Siegfried Kracauer (Estética sin territorio 219), para quien en el Berlín de la década de 1920 era evidente un amplísimo culto a la distracción, que no hacía peligrar a la verdad; peligro que provenía, por el contrario, de la afirmación de valores culturales que se habían vuelto irreales, por el abuso de conceptos como personalidad, interioridad y tragedia que poco decían ya sobre la vida de los sujetos modernos. Estos sujetos, más concretamente el público berlinés, actuaba conforme a la verdad, cuando prefería el fulgor de las estrellas de las películas y las revistas musicales, a las formas artísticas tradicionales. Por supuesto, las salas de cine, lugares principales del culto a la distracción, no habían realizado su verdadera vocación estética, lo cual solo era posible, cuando cumplieran también su vocación social, es decir cuando "liberen sus representaciones de todos los ingredientes que privan al cine de sus derechos y apunten radicalmente hacia una distracción que ponga al descubierto la desintegración, y que no la oculte. Podrían hacerlo en Berlín, donde viven las masas que, si se dejan narcotizar fácilmente, es sólo porque se encuentran cerca de la verdad" (Kracauer 223). Esta labor de poner al descubierto la doble desintegración del mundo perceptivo y de las películas, será desarrollada ejemplarmente por los kinoks en El hombre de la cámara, filme que hace visible la fragmentación de las tomas, su síntesis a través del montaje, y la relación de estos procedimientos con la percepción y vivencias propias de la vida urbana, punto que será ampliado posteriormente.

En un bello ensayo en el cual la figura del escritor ruso Nikolai Leskov sirve como punto de partida para una reflexión mucho más amplia, Benjamin plantea la desaparición del aburrimiento en las ciudades y su declive en el campo. La importancia de este hecho se debe a que "el aburrimiento es ese ave que incuba el huevo de nuestra experiencia" ("El narrador. Consideraciones sobre la obra de Nikolái Léskov" 49), la huida de ese ave trae consigo la perdida de la capacidad de escucha y 
el desvanecimiento de la comunidad de oyentes; capacidad y comunidad necesarias también para la narración que es necesariamente colectiva, experiencial y fundamental para estar en el lenguaje con los otros y fundar una cultura. Desde el punto de vista benjaminiano, la narración se contrapone a la novela y a la información. A la primera la considera una forma artística individualizante por excelencia, ya que si bien fue común que las novelas fueran "narradas" a través de la lectura en voz alta, sus formas de producción y apropiación convencionales requerían un sujeto relativamente aislado y ensimismado. A la segunda, le atribuye la desaparición del carácter artesanal de la comunicación y de los elementos maravillosos de la narración; la información cuyo formato principal era el periódico, representaba la producción industrial de las noticias, el privilegio de lo plausible sobre lo maravilloso, el acercamiento de lo lejano, y el consumo rápido y repetido de acontecimientos heteróclitos. Se está de nuevo ante el principio del montaje, que expresa la concordancia y la contemporaneidad de la información con un estado de la técnica y de la sociedad, el cual cobra aún mayor fuerza con el cine.

La decadencia de la narración está vinculada con la puesta en evidencia de la crisis del aura, con el declive de la tradición y de la experiencia (Erfahrung), y con el surgimiento de una nueva barbarie, la cual era deseada por mucha de la gente "culta", quien buscaba multiplicar sus vivencias (Erlebnisse). Esto se debe también a la evidencia de una finitud, al cuestionamiento de la trascendencia de lo humano:

Pues ninguna experiencia fue desmentida con más rotundidad que las experiencias estratégicas a través de la guerra de trincheras, o las experiencias económicas mediante la inflación; las experiencias corporales por el hambre; las experiencias morales por los que ejercían el gobierno. Una generación que fue al colegio todavía en tranvía de caballos se encontraba ahora a la intemperie y en una región donde lo único que no había cambiado eran las nubes; y ahí, en medio de ella, en un campo de fuerzas de explosiones y torrentes destructivos, el diminuto y frágil cuerpo humano (“Experiencia y pobreza” 217).

Ante este panorama, los seres humanos se encontraban completamente agotados e incapaces de llevar sobre sus hombros el peso de la tradición y los bienes culturales.

En Walter Benjamin hay un rechazo a la historia cultural como inventario de los bienes culturales, es decir, de esa idea de grandes hombres que producían grandes obras. Para él ("Sobre el concepto de historia" 309), estos bienes son el botín del cual se han apropiado los poderosos, pero que debe su existencia a la servidumbre anónima de miles de personas. Imposible no recordar "Las preguntas de un obrero lector" de Bertold Brecht, poema en la cual se cuestionó frontalmente la autoría de esos bienes culturales, generalmente atribuidos a los sectores dirigentes, pero que desde una perspectiva materialista como la de Brecht y Benjamin, responderían al esfuerzo de los miles de obreros que vivieron y murieron para realizarlos. En este sentido, las evidencias materiales del esplendor cultural, son al mismo tiempo las huellas imbo- 
rrables de la barbarie y de la explotación, de una barbarie que se perpetúa a través de la transmisión de estos bienes de una generación a otra.

Casi al mismo tiempo que los dos autores citados en el párrafo precedente cuestionaban las ideas tradicionales sobre la cultura, el cineasta francés Abel Gance estrenaba su monumental película Napoleón (1927), verdadera apología a la heroicidad de esa figura histórica. Ese mismo año Gance publicó un artículo que Benjamin citará para a través de la oposición, enfatizar su punto de vista: “En el 1927 Abel Gance exclamó con entusiasmo "Shakespeare, Rembrandt, Beethoven harán cine... Todas las leyendas, las mitologías y los mitos, todos los fundadores de religiones, e incluso las religiones en su conjunto... esperan su luminosa resurrección, mientras los héroes se agolpan en las puertas". A esta general liquidación nos invitaba, inconsciente, el cineasta" " $L a$ obra de arte...”, tercera redacción 55-6). Lo que para Gance (“¡Ha llegado el Tiempo de la Imagen!" 460-1) implicaba una resurrección colectiva por medio de la inclusión de la tradición en el “Tiempo de la Imagen”, para Benjamin era la ilustración innegable de la liquidación del aura de los héroes y los mitos, de su unicidad y singularidad, en definitiva, su conversión en mercancías reproducibles infinitamente. Sin duda se trataba de dos formas completamente diferentes, e incluso opuestas de comprender un medio relativamente nuevo en ese momento.

\section{VI}

El error de Gance consistiría en tratar de imponer o descubrir rasgos de "culto" en el cine, para transformarlo en un arte reconocido socialmente. Para Benjamin, estos intentos eran imposibles de cumplir, por un lado, e indeseables por el otro, puesto que la pregunta relevante no era si el cine era o no un arte, sino cómo transformaba el aparato cinematográfico - y antes que él la fotografía- la noción de arte al reconfigurar la sensibilidad de las masas ("La obra de arte...", tercera redacción 63). El fracaso de iniciativas, como las de la empresa Film d'Art, consistentes en adaptar obras teatrales prestigiosas, en muchas ocasiones con los mismos actores que las habían representado en escena, mostraban la imposibilidad de auratizar el cine. La figura del actor es ilustrativa, los actores teatrales actuaban ante el público, cada representación era única e irrepetible aunque las funciones se sucedieran cada noche; mientras los actores cinematográficos lo hacían ante las cámaras, lo que implicaba que los segundos no podían modificar su actuación acorde a las reacciones de los espectadores, al tiempo que estaban sometidos constantemente a test ópticos completamente condicionados por la técnica cinematográfica, la cual fragmentaba y hacía discontinua la interpretación, que se descomponía en muchas actuaciones individuales y aisladas, dada la disponibilidad de los decorados, los otros actores, los técnicos, pero sobre todo, de las necesidades del montaje y de la reducción de costos, todo esto llevaba a que 
el actor cinematográfico no actúa ante un público, sino ante un aparato. El operador ocupa exactamente el lugar que en el examen de aptitud ocupa el individuo que controla las pruebas. Actuar a la luz de los sunlights satisfaciendo al tiempo las condiciones propias del micrófono es exigencia de primer nivel. El estar a su altura significa sin duda conservar la humanidad frente al aparato. El interés de esta actuación se hace así enorme. Pues ante un aparato es ante lo que la enorme mayoría de los habitantes de ciudades debe en las oficinas $\mathrm{y}$ en las fábricas abdicar de su humanidad durante la jornada de trabajo. Y, por la tarde, esas mismas masas van a llenar los cines para vivenciar cómo el actor cinematográfico se toma la revancha en nombre de ellas al no sólo afirmar su humanidad (o lo que a ellas tal se les parece) frente al aparato, sino al hacerlo útil para su triunfo personal (“La obra de arte..." primera redacción 28 , énfasis agregado).

Esta revancha tiene como condición de posibilidad la ausencia de aura, ya que se ha perdido el aquí y ahora de la interpretación, ésta es repetible, cercana y transportable. A diferencia de la actuación teatral que sufre ligeras modificaciones de función en función y que depende de la coexistencia del actor y su público, la actuación cinematográfica está fijada en un soporte, lo cual hace que caracterizarla como repetible cobre sentido, al tiempo que permite que las películas no sean definidas solamente por el movimiento de las imágenes en la pantalla, sino también por la circulación transnacional de esas imágenes, por su capacidad de desplazarse y diseminarse, capacidad que depende de la técnica cinematográfica y la conversión de las películas en mercancías ${ }^{3}$. El aparato cinematográfico como expresión privilegiada de la segunda técnica, aquélla que ya no ayuda a los seres humanos a dominar la naturaleza, sino que se convierte ella misma en naturaleza, se fundamenta en la divisa "una vez no es nada", a diferencia de la primera técnica, de carácter ritual o cúltica, basada en el "de una vez por todas" ("La obra de arte en la época de su reproducción mecanizada” $330-1$ ).

El actor seguía, entonces, teniendo que enfrentarse a los espectadores, es más lo tenía que hacer constantemente, pero lo hacía ahora como una mercancía ante sus consumidores. A la desaparición del aura el cine capitalista respondía con la creación de estrellas, expresiones de una lejanía que sí podía ser acercada y que efectivamente lo era, no solamente a través del consumo de las películas, sino también de las revistas, la radio, los carteles y los eventos públicos. A la conversión del actor en mercancía, Vertov reaccionaría suprimiéndolo, como se verá luego.

La pérdida del aura afectaría a la par de los actores, también a los técnicos. Walter Benjamin planteó una comparación para ilustrar la cercanía inherente a la labor de

3 Cf. Benjamin "La obra de arte en la época de su reproductibilidad técnica" (Primera redacción) (29) y Rutsky "Walter Benjamin and the Dispertion of Cinema"(13). 
los operadores de cámara. Esta comparación estuvo compuesta por cuatro términos: cirujano, mago, pintor y operador. El mago cura al enfermo con la imposición de sus manos, mientras el cirujano interviene a su paciente. El mago mantiene, entonces, la distancia entre él y el enfermo, da un paso hacia éste a través de la imposición de manos, pero da muchos hacia atrás con el incremento de su autoridad; el cirujano aumenta un poco la distancia con la destreza de su intervención, pero la disminuye notablemente con la necesidad de penetrar en lo más profundo de su paciente, pero de una forma por completo "operatoria". Así, mientras el mago y el enfermo hacen parte de la misma comunidad simbólica, lo que hace efectivo el tratamiento; la efectividad de la cirugía se fundamenta, en buena medida, en la conversión del cuerpo del paciente en materia indiferente -hyle-, es decir, en la ruptura de la comunidad humana entre quien interviene y quien es intervenido (Buck-Morss, Walter Benjamin, escritor revolucionario 204), no en vano Benjamin planteaba que el cirujano evitaba enfrentarse con su enfermo de hombre a hombre, a lo que agregaba que la relación entre mago y cirujano era semejante a la del pintor y el operador de cámara: "El pintor observa en su trabajo la natural distancia con lo dado, y el cámara, en cambio, penetra a su vez profundamente en la red de datos. Las imágenes que obtienen uno y otro son enormemente diferentes. La del pintor es total; múltiplemente troceada la del cámara, cuyas partes se juntan según una ley nueva" ("La obra de arte...", tercera redacción 73), ley que Vertov buscará llevar a sus últimas consecuencias en sus investigaciones cinematográficas y que solo serán posibles en un aparato postaurático o, más exactamente, en un aparato que contribuyera a crear esa era posterior al declive del aura.

\section{VI}

El cine no sólo se caracterizaba por la manera como los seres humanos se presentaban ante la cámara o por cómo la manipulaban, era más importante aún como todo el aparato configuraba la realidad sensible y abría posibilidades que anteriormente no estaban disponibles. Si los sujetos modernos eran caleidoscopios móviles y conscientes (“Sobre algunos motivos en Baudelaire" 234) el cine les proporcionaba imágenes y los hacía ver más allá, hacía cognoscible lo que se había visto sin saber que se había visto -el inconsciente óptico-, en definitiva permitía ver y sentir de otra manera:

con el primer plano se ensancha el espacio, con el ralentí el movimiento. Y al igual que en la "ampliación no se trata de clarificar lo que se ve borroso "en todo caso", sino que más bien se hacen manifiestas formaciones estructurales de la materia que se revelan completamente nuevas, tampoco el ralentí hace tan sólo que se manifiesten los motivos conocidos de nuestros movimiento, sino que en esos conocidos descubre algunos desconocidos totalmente "que no funcionan ahí en absoluto en calidad de identificaciones de movimientos rápidos, sino 
peculiarmente deslizantes, flotantes y como supraterrenales". Se hace entonces patente que es otra distinta naturaleza la que habla a la cámara que la que le habla al ojo (“La obra de arte...", tercera redacción 77).

El cine hacía posible la expansión de la naturaleza visible, puesto que era el resultado de la profunda penetración -análoga a la del cirujano- del equipamiento técnico en la realidad. Para Benjamin técnica y naturaleza son fenómenos que se constituyen mutuamente; en la época en la que prima el valor de culto la técnica está subordinada al ritual, y en este sentido no se diferencia claramente de la magia, con el declive del valor de culto, la técnica se libera y se impone como segunda naturaleza, que debe ser de nuevo apropiada por los seres humanos a través de un aprendizaje, en el cual el cine tendrá un papel central, ya que posibilita el despliegue de nuevas apercepciones y reacciones, abre, pues, la posibilidad de una inervación colectiva de las masas. En este sentido, la técnica liberaba a los seres humanos de la naturaleza, convirtiéndose en una segunda naturaleza; el carácter técnico de esta segunda naturaleza era la razón por la cual el aparato cinematográfico podía penetrar profundamente en ella y ampliar la visibilidad del mundo. Una naturaleza técnica solo podía hacerse visible en su complejidad a través de una mediación técnica. En definitiva, no había posibilidades de escapar de la percepción mediada por los aparatos, solo diversas formas de usar sus posibilidades que podían ser más o menos emancipadoras.

El cine poseía una doble potencialidad, podía ser el aparato “anestésico” por excelencia o podía producir una nueva sensibilidad como se ha planteado con anterioridad, para esto último era necesario formas colectivas de recepción cinematográfica que a través de la inervación revirtieran los efectos catastróficos de la técnica moderna (Rutherford, "Mimetic innervations" 285). En la primera versión de "El ensayo sobre la obra de arte en la época de su reproductibilidad técnica”, Benjamin planteó una de las posibilidades de inervación, se trataba de la apropiación colectiva de percepciones individuales, como aquellas del soñador o del psicótico, así si la tecnificación producía comportamientos psicóticos en las masas, también producía una inmunización a través de ciertas películas, en las que se desarrollaban las fantasías sádicas y los delirios masoquistas, reconduciéndolas al estallido de la carcajada colectiva ${ }^{4}$. Mientras para Horkheimer y Adorno, el pato Donald era el ejemplo de que los golpes había que soportarlos (147), para Benjamin el Mickey Mouse políticamente incorrecto de la década de 1920 y principios de la década de 1930, mostraba las argucias de los pequeños y débiles; Charles Chaplin sería otro representante de estas artimañas y tendría, además, la ventaja de ser propietario de los medios de producción artísticos con los que trabajaba Useros ("El misterio Chaplin" 87).

4 Cf. Benjamin, "La obra de arte en la época de su reproductibilidad técnica" (Primera redacción), (39) y Hansen, Cinema and Experience. Siegfried Kracauer, Walter Benjamin, and Theodor W. Adorno (164-5). 
El estallido de las carcajadas mencionado correspondería a una inervación colectiva propia de una sociedad en la cual las relaciones de propiedad se encontraban desfasadas de las fuerzas productivas -desfase que la guerra "resolvía" al movilizar los medios técnicos conservando las relaciones de propiedad- ("La obra de arte..., tercera redacción 83-4). No obstante, y como toda inervación era una excitación corporal colectiva, un modo de acción en el cual había una reapropiación del cuerpo por sí mismo y un redescubrimiento de la materialidad gracias al universo técnico (Tackels, Walter Benjamin 603). Además, la inervación era potencialmente, una descarga revolucionaria caracterizada por la interrupción, la instantaneidad y la intensidad.

\section{VII}

La noción de inervación desaparece en la tercera versión de "El ensayo sobre la obra de arte", pero la idea de las potencialidades revolucionarias de la recepción colectiva de las películas subsiste. Benjamin planteaba que las masas se veían involucradas en el vaivén entre atención y distracción, para el cual el cine proporcionaba un entrenamiento, puesto que los espectadores debían estar atentos a las imágenes que se desplegaban ante ellos, al tiempo que debían interrumpir constantemente las asociaciones que estas imágenes les provocaban para recibir las imágenes -fotogramas y planos- que se proyectaban inmediatamente después. En un trabajo imprescindible, para comprender las formas perceptivas surgidas durante el siglo XIX, Jonathan Crary (Suspensiones de la percepción 55) ha criticado duramente a Benjamin, Simmel, Kracauer y Adorno, por asumir que la distracción era una característica fundamental de la subjetividad moderna; en su opinión esto dejaba de lado una parte fundamental de los procesos de subjetivación, los cuales estaban relacionadas con múltiples técnicas, instituciones, prácticas y discursos que buscaban que los sujetos atendieran. Sin embargo, lo que Crary no comprende es que Benjamin y los otros pensadores que señala, no oponían la distracción a la atención necesaria para desempeñarse como obrero industrial o como público de un espectáculo masivo, sino que el recogimiento propio del juicio estético era confrontado por la recepción en distracción característica del mundo moderno. Esta oposición implicaba que en la primera modalidad el sujeto estético se sumergía en la obra, mientras en la segunda, la masa sumergía la obra en sí. "La arquitectura fue siempre prototipo de una obra de arte cuya recepción se da distraídamente, y además, por el colectivo. Así, las leyes de su recepción son las más instructivas que tenemos" ("La obra de arte...", tercera redacción 82). La modernización de la percepción expandía e intensificaba esta forma de recepción, que no era exclusivamente óptica, sino también táctil y dependía de la repetición y la costumbre.

En este orden de ideas, la profundización de la apercepción que el aparato cinematográfico traía consigo planteaba a la par de una visión óptica, una visión háptica, táctil (Gasché, “The Deepning of Apperception: On Walter Benjamin’s Theory of Film” 
32). El cine como aparato de acercamiento de lo lejano propiciaba el impacto o choque -shock- literal de los espectadores con la vertiginosa, constante e imparable sucesión de fotogramas, planos, escenas y secuencias que eran apropiados de forma colectiva. El scanning (Déotte La ciudad porosa 24) realizado por el público cinematográfico le permitía enfrentarse a las películas, apropiárselas y realizar juicios sobre éstas, pero desde la recepción en la distracción. Es decir, el juicio esquivaba la contemplación, tal y como se hacía en la apropiación de las obras arquitectónicas. A diferencia de la forma convencional de relacionarse con una pintura o una escultura, que implica una inversión tiempo y una labor de focalización, los colectivos que viven, trabajan o visitan una construcción se apropian de ella, generalmente, de forma distraída, sus ojos rozan las paredes, los techos, las columnas, construyen con la visión háptica la tridimensionalidad del edificio.

A pesar de sus diferencias, el cine configura una sensibilidad colectiva similar a la producida por la arquitectura, sobre todo por la arquitectura moderna de vidrio y hierro. El "efecto del tren", mito fundador del cinematógrafo (Bottomore 1999), puede ser interpretado desde esta perspectiva; el pánico de la audiencia, que por supuesto debe ser matizado y seguramente no provocó la estampida que algunos medios describieron, estuvo relacionado con el shock producido por el rápido acercamiento del tren que llegaba a la estación de La Ciotat, shock que dio lugar a una descarga de energía psíquica, que a su vez produjo una descarga somática. Esta inervación no era muy diferente a la que esos mismos individuos y sus descendientes debían enfrentar todos los días en las ciudades de principios del siglo XX, como lo muestra la modalidad documental de las sinfonías urbanas, en la cual vemos a numerosas personas pasar temerariamente entre tranvías, automóviles y carruajes que circulan velozmente. De esta forma, estos cambios en el aparato perceptivo, tenían una clara correspondencia con "aquellas que, en la privacidad de su existencia, experimenta todo transeúnte en el tráfico de una gran ciudad, y, en la escala de la historia universal, todo luchador que se levante contra el orden social de nuestros días" ("La obra de arte...", primera redacción 42 ).

\section{VIII}

En la década de 1930, los luchadores se enfrentaban al fascismo. La desauratización del mundo entronizaba a la par de la estrella cinematográfica al dictador o incluso volvía al dictador estrella, como lo ilustra El triunfo de la voluntad. El Estado totalitario, aún más que el cine, se conformaba como la obra de arte total por excelencia de las primeras décadas del siglo XX y se volvía un fin en sí mismo, por lo cual no se detenía ante el sacrificio de los individuos, que eran transformados en cuerpos dóciles -hyle-que podían ser intervenidos y sacrificados, haciendo de este sacrificio

5 En la tercera redacción de este ensayo la palabra "luchador" es reemplazada por "todo ciudadano". 
un espectáculo "Así sucede con la estetización de la política que propugna el fascismo. Y el comunismo le responde por medio de la politización del arte" ("La obra de arte...”, tercera redacción 85), dicha politización no es explicada por el autor. En los ensayos que Benjamin dedicó a su amigo Bertold Brecht y en algunos otros escritos se encuentra una tentativa de respuesta.

La importancia de Brecht, en este orden de ideas, fue la superación de los elementos cúlticos que sobrevivían en el teatro moderno; a través de la desaparición, aunque sea parcial, de la orchestra que separaba a actores y público (“¿Qué es el teatro épico? (1). Estudio sobre Brecht” 123). La distancia era abolida, lo lejano se acercaba y la recepción se daba en la distracción por parte de un colectivo interesado (“¿Qué es el teatro épico?” (2) 136). El trabajo de Brecht atrajo profundamente a Benjamin por que no trataba simplemente de difundir un "mensaje político", sino que buscaba reconfigurar el teatro, transformar el medio de producción en sí mismo. El teatro épico daba una respuesta a la pregunta por "cómo estaba la obra en las relaciones de producción?, esta pregunta se refería de inmediato a la función de esa obra dentro de las relaciones de producción literaria [o dramatúrgica] de una época. O, en otras palabras: se refiere inmediatamente a la técnica literaria de las obras" ("El autor como productor..." 299-300), lo que nos remite a una pregunta por la técnica, pero desde la crítica cultural materialista.

Ignorar esta pregunta es preocuparse por los contenidos políticos, ignorando que estos por bien intencionados que estén generalmente transformaban la miseria en objeto de consumo y la lucha contra ésta en un espectáculo. Para Walter Benjamin se trataba de disolver las formas canónicas burguesas y reutilizar sus ruinas. Más que trabajar en los productos se trataba de trabajar sobre los medios de producción. Esto implica una función organizadora consistente en adaptar los medios de producción a los fines revolucionarios, es decir, socializar los medios de producción espiritual, lo cual llevaría justamente a que dejaran de ser "espirituales", a que el trabajo creativo no fuera más una modalidad de trabajo privilegiada sino que se expandiera por toda la sociedad.

Esta función organizadora tenía como principios fundamentales: 1) iniciar a otros productores y 2) darles unos aparatos mejorados. Al confrontar la experiencia soviética Benjamin ${ }^{6}$ se concentró en los escritores, los periódicos y el teatro de este país más que en el cine soviético de su época, el cual aparentemente no conoció en profundidad. El interés de muchos artistas rusos por abandonar las formas artísticas tradicionales llamó profundamente la atención de Benjamin; para ellos el artista debía volverse un ingeniero y diseñar objetos útiles o carteles que pudieran ser leídos y comprendidos por los proletarios. No se trataba, pues, de crear mensajes correctos políticamente, sino de llegar al pueblo y convertir a los consumidores en productores, no en vano buena parte de la creación era colectiva y tenía como modelo las fábricas, "Así, en

6 En "Programa de un teatro infantil proletario" "El agrupamiento político de los escritores rusos", "Nueva literatura en Rusia" y "El periódico" (Obras. Libro II / Vol. 2). 
Rusia, hoy leer es más importante que escribir; y leer el periódico es más esencial que leer libros; y enseñar a leer es más importante todavía que leer el periódico" ("El agrupamiento político de los escritores rusos" 363).

La mención a los periódicos no era gratuita, la prensa como principal canal de difusión de la información, provocaba la desaparición de unas formas de comunicación y de comunidad, pero hacía posible otras. De forma similar a la supresión de la orchestra, el periódico cuestionaba profundamente la separación entre escritores y lectores, puesto que la competencia para escribir ya no se basaba en una formación especializada sino en una instrucción general, que llevaba a que en el lugar principal de la degradación de la palabra, se incubará su salvación, al permitir el acceso a la escritura a quienes hasta hacía poco estaban condenados a ser eternos lectores ("El periódico" 240). Estos cambios que en el ámbito de la escritura habían demorado siglos, se cumplían en el transcurso de unos cuantos años en el cine, "Pues en la praxis del cine -sobre todo del ruso- tal desplazamiento ya se ha realizado esporádicamente. Una parte de los actores que se encuentran en el cine ruso ya no son actores en nuestro sentido, sino personas que se interpretan a sí mismas, y por cierto, antes que nada, inmersas en su proceso de trabajo" ("La obra de arte...", tercera redacción 72), estrategia que tendrá en los kinoks a sus principales defensores en la Unión Soviética de las décadas de 1920 y 1930.

\section{IX}

Benjamin (“La obra de arte...", tercera redacción, 70) relaciona explícitamente la aspiración de todo ser humano de ser filmado con Tres cantos para Lenin (1933) dirigida por Dziga Vertov, de quien también menciona La sexta parte del mundo (1926) en "La situación del arte cinematográfico en Rusia”. Estas referencias estaban plenamente justificadas, en tanto el cine-ojo liderado por Dziga Vertov buscó constituirse en un frente de cine documental sin actores, en el cual el ser humano corriente se apoderara de la pantalla, a lo que se sumaba otra serie de premisas y prácticas que hacen del trabajo de este director y sus kinoks uno de los intentos más sistemáticos por politizar el arte; politización que llevaría a su desaparición como arte, es decir, como una esfera relativamente autónoma. A pesar de esta confluencia, es necesario recordar que las relaciones explícitas entre la praxis intelectual de Benjamin y la praxis cinematográfica de Vertov fueron débiles.

$\mathrm{Al}$ igual que Benjamin, Vertov consideraba que el aparato cinematográfico poseía numerosas posibilidades que se veían constreñidas por su nacimiento en un mundo capitalista, para desarrollarlas este cineasta planteaba la necesidad de lograr una cuadruple liberación. En primer lugar, el cine debía ser liberado de la tutela del capital, condición indispensable para iniciar a otros productores y mejorar el aparato cinematográfico. A semejanza de cualquier otra máquina que funcionaba bajo un modo de producción capitalista, las cámaras y los proyectores cinematográficos debían ser resituados dentro de otro modo de producción que los pusiera 
al servicio de la emancipación humana no de su subordinación, lo cual implicaba una transformación de las relaciones de producción cinematográfica. Con este propósito Vertov, impulsó la formación de trabajadores del cine que denominó kinoks, agrupados en torno a una o varias cine-estaciones experimentales, que debían funcionar de forma análoga a las fábricas y que debían contar con medios de transporte rápidos, películas de alta sensibilidad, cámaras y aparatos de iluminación pequeños y livianos, y equipos de cine-reporteros y de cine-observadores. Todo esto permitiría trabajar varios temas simultáneamente, que podían servir a una o varias películas, perfeccionar las actividades de información, organización, rodaje y montaje, para mejorar la calidad sin aumentar el presupuesto, reciclar material de un proyecto a otro y evitar los tiempos muertos. Se trataba, pues, de establecer las bases materiales y organizativas necesarias para captar la vida de improviso. Bases que pasaban por un trabajo colectivo, aunque en ocasiones Vertov (2011) entrará en verdaderas apologías de sí mismo, dejando de lado a sus colaboradores, como lo atestiguan sus diarios.

En segundo lugar y atendiendo a la vida socialista que emergía, era necesario liberar al cine del arte para documentar la ruptura de los viejos esquemas ante el avance imparable del "rodillo compresor de la Revolución" y testimoniar "el crecimiento del joven organismo soviético" (Memorias de un cineasta bolchevique 207). Esta tarea era imposible, si las películas seguían siendo cine-ilustraciones de literatura, de música, de teatro... es decir, un cine-opiaceo y seductor, pero leproso, del cual había que huir, pues traía consigo la ceguera, como afirmaba Vertov. La respuesta era un cine-ojo, un cine visionario en el cual la vida se le presentará de improviso al espectador, un cine sin guion y sin puesta en escena, un cine rebosante de hechos. En este sentido, el trabajo de los kinoks se ejercía en el dominio de "la vida cotidiana y su organización", no en el del "arte y la vida cotidiana" e iba por lo tanto en contravía de los intentos de re-auratización del aparato cinematográfico.

En tercer lugar, había que liberar a la cámara de la servidumbre de la visión humana. Para Vertov era claro que los ojos de los seres humanos no podían ser mejorados, pero la visión sí. En este sentido, era completamente insensanto usar la cámara cinematográfica para reproducir la percepción "natural". Este aparato permitía nuevas condiciones de visibilidad, basadas en la captación de movimientos que se escapaban a la percepción de los hombres y de las mujeres: "Yo soy el cine-ojo. Soy el ojo mecánico. Yo, máquina, les muestro el mundo como únicamente yo puedo verlo" (Memorias de un cineasta bolchevique 179). El uso de esta protesis de la visión permite acceder a lo que Walter Benjamin denominó inconsciente óptico, que como se señaló en apartados anteriores establecía una nueva relación entre lo visto y lo conocido, y le abría a las masas "una nueva región de la consciencia" ("Réplica a Oscar A. H. Schmitz" 369) al tiempo que les permitía descomponer y hacer comprensible su entorno doméstico, laboral y de ocio. En este sentido, el ojo humano en su finitud y fragilidad no estaba capacitado para aprehender la complejidad de la segunda naturaleza, tarea destinada a la cámara. 
Gracias a ese ciclope biomecánico que conformaban el operador y su cámara, el desciframiento comunista del mundo se hacía posible y las relaciones entre la técnica y la naturaleza eran reconfiguradas. Por supuesto, el manejo de la cámara no debía ser dejado al libre albedrío del operador, debía, por el contrario, seguir el método de "la cámara invisible" basado en una serie de consignas como el rodaje preciso, veloz, disimulado, a distancia, en movimiento, desde arriba, etcétera, a lo cual se sumaría la filmación acelerada y ralentizada, se trataba de aprovechar todas las angulaciones, movimientos y posibilidades de la cámara.

En cuarto y último lugar, había que liberar al montaje de las constricciones del espacio y del tiempo burgués. De este modo, a las potencialidades de una cámara que ya no buscaba reproducir las carencias perceptivas del ojo humano, se sumaban las posibilidades abiertas por el montaje cinematográfico entendido como organización del mundo visible; el cual no tenía problema alguno en asociar fragmentos pertenecientes a diferentes tiempos y espacios, liberando de nuevo a los sentidos de sus límites orgánicos. Dicha asociación debía estar fundada en una dialéctica atenta al movimiento entre las imágenes, es decir, a los intervalos. Para Vertov al igual que para Benjamin, la fragmentación y velocidad eran inmanentes al mundo moderno. De esta manera, los documentales de los kinoks se oponían a las prácticas convencionales de Hollywood como los raccords de continuidad y la progresión narrativa, que según los planteamientos de Thomas Elsaesser ("Between Erlebenis and Erfahrung: Cinema Experience with Benjamin" 295) intentaban hacer pasar las vivencias (Erlebnisse), provocadas por la veloz sucesión de planos heteróclitos, por experiencias (Erfahrungen), lo cual era un intento nostálgico y reaccionario, en última instancia ideológico y condenado al fracaso, en tanto falseaba el carácter mecánico del aparato cinematográfico y buscaba re-auratizar la obra de arte.

El hombre de la cámara compendió todas las investigaciones realizadas por los kinoks, durante la década de 1920. En esta película, se establecía una distancia clara con el cine-ilustración y se buscaba captar la vida de improviso ${ }^{7}$. En ella se desplegó todo un esfuerzo por llevar al límite la versatilidad de la cámara y por sintetizar el espacio y el tiempo, no en vano la película construía un día en la vida de la ciudad, día que estaba conformado por el ensamblaje de planos y secuencias provenientes de varios días y de varias ciudades.

A través de estas secuencias, Dziga Vertov mostraba las relaciones que vinculaban a los trabajadores entre sí, y al trabajo con sus efectos: el consumo y el ocio. La segunda parte de la película oponía, a su vez, el ocio creativo y el descanso merecido al consumo de alcohol y a la superstición. Tanto en la jornada laboral como en el descanso, el verdadero movimiento entre los planos es el movimiento del trabajo, el cual tenía como horizonte deseado tanto para Benjamin como para Vertov, la

7 Lo cual no excluye la puesta en escena, pero se trata de una puesta en escena en la cual los trabajadores aparecen como trabajadores, incluyendo al operador de cámara, la editora o los músicos. 
conversión del autor en productor y del productor en autor; no se trataba de hacer de todo hombre un artista, más bien todo artista debía transformarse en un trabajador y todo trabajo debía ser creativo.

De esta forma, la totalidad social que las películas de los kinoks construían eran el resultado de la suma de los intervalos de varios movimientos sociales (Beller, "Dziga Vertov and the Film of Money" 160), los cuales unían a los trabajadores soviéticos, haciendo evidente su complementariedad e interdependencia, es decir haciendo visible lo que el cine capitalista velaba o en otras palabras, usando la mediación del aparato cinematográfico para mostrar el carácter inmanentemente técnico de la segunda naturaleza, es decir de la naturaleza propia de los seres humanos contemporáneos. En este sentido, estas películas y en especial El hombre de la cámara, pueden y muy posiblemente deben ser entendidas como obras plenamente post-auráticas, en las cuales las posibilidades del cine fueron llevadas tan lejos que chocaron con la indiferencia de la dirigencia soviética. Tal vez, como lo propone Manovich (2005) Vertov nos interpele a nosotros aún más de lo que interpeló a sus contemporáneos, algo similar podría plantearse de Walter Benjamin; ambos son imágenes que relampaguean ante nosotros en estos momentos de peligro, es nuestra tarea apoderarnos de ellos.

\section{Referencias}

Adorno, Theodor W. Crítica cultural y sociedad. Trad. Manuel Sacristán. Barcelona: Ariel. 1970. Medio impreso.

---. "Sobre el carácter fetichista de la música y la regresión de la escucha”. Disonancias. Introducción a la sociología de la música. Obra completa 14. Rolf Tiedemann (Ed.). 15-50. Madrid: Akal, 2009. Medio impreso.

Arendt, Hanna. Walter Benjamin; Bertolt Brecht; Hermann Broch, Rosa Luxemburgo. Trad. Luis Izquierdo y José Cano Templeque. Barcelona: Anagrama, 1971. Medio impreso.

Aumont, Jacques. Las teorías de los cineastas. La concepción del cine de los grandes directores. Trad. Carlos Roche. Barcelona: Paidós, 2004. Medio impreso.

Barría, Mauricio. "La producción de un desaparecimiento. Verdad, aura y técnica en Walter Benjamin”. Aisthesis. 49 (2011): 192-204. Medio impreso.

Beller, Jonathan. "Dziga Vertov and the Film of Money". Boundary 2 26, 3(1999): 151-199. Medio impreso.

Benjamin, Walter. "Ciudad y arquitectura oníricas, ensoñaciones utópicas, nihilismo antropológico, Jung”. Libro de los pasajes. Rolf Tiedemann (Ed.). Madrid: Akal, 2007a. Medio impreso.

---. “Teoría del conocimiento, teoría del progreso”. Libro de los pasajes. Rolf Tiedemann (Ed.). Madrid: Akal, 2007b. Medio impreso.

---. "Pequeña historia de la fotografía”. Obras. Libro II / Vol. 1. Rolf Tiedemann 
y Hermann Schweppenhäuser (Eds.). 377-403. Madrid: Abada, 2007c. Medio impreso.

---. "Experiencia y pobreza”. Obras. Libro II / Vol. 1. Rolf Tiedemann y Hermann Schweppenhäuser (Eds.). 216-222. Madrid: Abada, 2007d. Medio impreso.

---. "La obra de arte en la época de su reproductibilidad técnica". (Tercera redacción).

Obras. Libro I / Vol. 2. Rolf Tiedemann y Hermann Schweppenhäuser (Eds.).

49-85. Madrid: Abada, 2008 ${ }^{\text {. }}$ Medio impreso.

---. "La obra de arte en la época de su reproductibilidad técnica”. (Primera redacción).

Obras. Libro I / Vol. 2. Rolf Tiedemann y Hermann Schweppenhäuser (Eds.).

7-47. Madrid: Abada, 2008b. Medio impreso.

---. "Sobre algunos motivos en Baudelaire”. Obras. Libro I/ Vol. 2. RolfTiedemann y Hermann Schweppenhäuser (Eds.). 205-259. Madrid: Abada, 2008c. Medio impreso. ---. "Sobre el concepto de historia”. Obras. Libro I / Vol. 2. Rolf Tiedemann y Hermann Schweppenhäuser (Eds.). 303-318. Madrid: Abada, 2008d. Medio impreso.

---. "La obra de arte en la época de su reproducción mecanizada". Obras. Libro I / Vol.

2, Rolf Tiedemann y Hermann Schweppenhäuser (Eds.). 323-353. Madrid: Abada, 2008e. Medio impreso.

---. "La situación del arte cinematográfico en Rusia”. Obras. Libro II / Vol. 2. Rolf

Tiedemann y Hermann Schweppenhäuser (Eds.). 363-367. Madrid: Abada, 2009a. Medio impreso.

---. "Réplica a Oscar A. H. Schmitz". Obras. Libro II / Vol. 2. Rolf Tiedemann y Hermann Schweppenhäuser (Eds.). 367-371. Madrid: Abada, 2009b. Medio impreso.

---. "Eduard Fuchs, coleccionista e historiador". Obras. Libro II / Vol. 2. Rolf Tiedemann y Hermann Schweppenhäuser (Eds.). 68-109. Madrid: Abada, 2009c. Medio impreso.

---. "El narrador. Consideraciones sobre la obra de Nikolái Léskov". Obras. Libro II / Vol. 2. Rolf Tiedemann y Hermann Schweppenhäuser (Eds.). 41-68. Madrid: Abada, 2009d. Medio impreso.

---. “Qué es el teatro épico? (1). Estudio sobre Brecht”. Obras. Libro II / Vol. 2. Rolf Tiedemann y Hermann Schweppenhäuser (Eds.). 123-136. Madrid: Abada, 2009e. Medio impreso.

---. ¿Qué es el teatro épico?” (2). Obras. Libro II / Vol. 2. Rolf Tiedemann y Hermann Schweppenhäuser (Eds.). 136-144. Madrid: Abada, 2009f. Medio impreso.

---. "El autor como productor. Discurso en el Instituto para el Estudio del Fascismo en París, el 27 de abril de 1934". Obras. Libro II / Vol. 2. Rolf Tiedemann y Hermann Schweppenhäuser (Eds.). 297-315. Madrid: Abada, 2009g. Medio impreso.

---. "El periódico". Obras. Libro II / Vol. 2. Rolf Tiedemann y Hermann Schweppenhäuser (Eds.). 239-240. Madrid: Abada, 2009h. Medio impreso.

---. "El agrupamiento político de los escritores rusos". Obras. Libro II / Vol. 2. Rolf Tiedemann y Hermann Schweppenhäuser (Eds.). 359-363. Madrid: Abada, 2009i. Medio impreso. 
---. "Nueva literatura en Rusia". Obras. Libro II / Vol. 2. Rolf Tiedemann y Hermann Schweppenhäuser(Eds.). 372-380. Madrid: Abada 2009j. Medio impreso.

---. "Programa de un teatro infantil proletario". Obras. Libro II / Vol. 2. Rolf Tiedemann y Hermann Schweppenhäuser(Eds.). 380-386. Madrid: Abada, 2009k. Medio impreso.

---. "Calle de dirección única”. Obras. Libro IV / Vol. 1. Rolf Tiedemann y Hermann Schweppenhäuser (Eds.). 23-89. Madrid: Abada, 2010. Medio impreso.

Bloch, Ernst. "Recuerdos de Walter Benjamin”. Trad. Guadalupe González. Minerva. 17 (2011). 25-27. Medio impreso.

Bottomore, Stephen. "The Panicking Audience? Early Cinema and the 'train effect". Historical Journal of Film, Radio, and Television 19, 2(1999). 177-216. Medio impreso.

Brea, José Luis. Las tres eras de la imagen. Imagen-materia, film, e-image. Madrid: Akal, 2010. Medio impreso.

Buck-Morss, Susan. Walter Benjamin, escritor revolucionario. Trad. Mariano López Seoane. Buenos Aires: Interzona, 2005. Medio impreso.

Burch, Noël. "Film's Institutional Mode of Representation and Soviet Response". October 11 (1979). 77-96. Medio impreso.

Costello, Diarnuid. “Aura, rostro, fotografía: releer a Benjamin hoy". Walter Benjamin: culturas de la imagen. Comp. Alejandra Uslenghi. 99-140. Buenos Aires: Eterna Cadencia, 2010. Medio impreso.

Crary, Jonathan. Suspensiones de la percepción. Atención, espectáculo y cultura moderna. Trad. Yaiza Hernández Velásquez. Madrid: Akal, 2008. Medio impreso.

Déotte, Jean-Louis. ¿Qué es un aparato estético? Benjamin, Lyotard, Rancière. Trad. Francisco Salas Aguayo. Santiago: Metales Pesados, 2012. Medio impreso.

---. La ciudad porosa. Walter Benjamin y la arquitectura. Trad. Natalia Calderón. Santiago: Metales Pesados, 2013 ${ }^{\text {a }}$ Medio impreso.

---. La época de los aparatos. Trad. Antonio Oviedo. Buenos Aires: Adriana Hidalgo, 2013b. Medio impreso.

Debray, Régis. Vida y muerte de la imagen. Historia de la mirada en Occidente. Trad. Ramón Hervás. Barcelona: Paidós. 2010. Medio impreso.

Elsaesser, Thomas. "Between Erlebenis and Erfahrung: Cinema Experience with Benjamin". Paragraph 32 (2009). 292-312. Medio impreso.

Gance, Abel. “¡Ha llegado el Tiempo de la Imagen!”. Textos y manifiestos del cine. Estética. Escuelas. Movimientos. Disciplinas. Innovaciones. Eds. Joaquim Romaguera i Ramió y Homero Alsina Thevenet. 455-464. Madrid: Cátedra, 2007. Medio impreso.

Gasché, Rodolphe.“The Deepning of Apperception: On Walter Benjamin's Theory of Film”. Mosaic 40 (2008). 27-39. Medio impreso.

Gerverau, Laurent. Histoire du visual au XX siècle. París: Éditions du Seuil, 2003. Medio impreso. 
Hansen, Miriam Bratu. Cinema and Experience. Siegfried Kracauer, Walter Benjamin, and Theodor W. Adorno. Berkeley: California University Press, 2012. Medio impreso. Horkheimer, Max y Theodor W. Adorno. "La industria cultural". Dialéctica de la ilustración. Obra completa, 3. Ed. Rolf Tiedemann. 133-181. Madrid: Aka, 2007. Medio impreso.

Jennings, Michael. "Walter Benjamin y la vanguardia europea”. Walter Benjamin: culturas de la imagen. Comp. Alejandra Uslenghi. 25-51. Buenos Aires: Eterna Cadencia, 2010. Medio impreso.

Kant, Immanuel. Crítica de la razón pura. Trad. Pedro Ribas. México D.F.: Taurus, 2013. Medio impreso.

Kracauer, Siegfried. Estética sin territorio. Trad. Vicente Jarque. Murcia: Colegio Oficial de Aparejadores y Arquitectos Técnicos de la región de Murcia, 2006. Medio impreso.

Manovich, Lev. El lenguaje de los nuevos medios de comunicación: la imagen en la era digital. Trad. Óscar Fontrodona. Barcelona: Paidós, 2005. Medio impreso.

Pezzella, Mario. Estética del cine. Madrid: A. Machado Libros, 2004. Medio impreso.

Quintana, Ángel. Después del cine. Imagen y realidad en la era digital. Barcelona: Acantilado, 2011. Medio impreso.

Rutherford, Anne. "Mimetic innervations". The Routledge Encyclopedia of Film Theory, Eds. Edward Branigan y Warren Buckland. 285-289. Oxon: Routledge, 2014. Medio impreso.

Rutsky, R. L. "Walter Benjamin and the Dispertion of Cinema”. Symplokē 15 (2007). 8-23. Medio impreso.

Santa Cruz, José Miguel. “Un repaso teórico (exhaustivo o no) al debate de la "muerte del cine” en el cine contemporáneo”. Aisthesis 55 (2014).155-177. Medio impreso.

Scholem, Gershom. Walter Benjamin y su ángel. Trad. Ricardo Ibarlucía y Laura Carugati. Buenos Aires. Fondo de Cultura Económica, 1998. Medio impreso.

Tackels, Bruno. Walter Benjamin. Una vida en los textos. Valencia: Universitat de València, 2012. Medio impreso.

Useros, Ana. "El misterio Chaplin". Mundo escrito. 13 derivas desde Walter Benjamin. Eds. Juan Barja y César Rendueles. 73-89. Madrid: Círculo de Bellas Artes, 2013. Medio impreso.

Valéry, Paul. "La conquista de la ubicuidad”. Piezas sobre arte, Paul Valery. 131-133. Madrid: Visor, 1999. Medio impreso.

Vertov, Dziga. Memorias de un cineasta bolchevique. Trad. Joaquín Jordá. Madrid: Capitán Swing, 2011. Medio impreso. 